A good example is the molluscan class of Cephalopods. Twenty-one species are shown; covering the nautili, cuttlefish, squids and octopi. A double page is given over to the Common Octopus so that individual characteristics [skin, beak, suckers, etc.] can be explained. The species are selected to show the diversity of forms, colours and life styles. Similarly there are 48 species of turtles, with a double page spread on the Aldabran Giant Tortoise. Examples have been chosen from around the world; from the cute $13 \mathrm{~cm}$ Spotted Turtle to the $1.2 \mathrm{~m}$ Galapagos Tortoise. The authors show that even the turtles simply designed shell can vary from smooth to knobby, soft to hard, patterned or plain.

Plants get a similar coverage. The orchids a represented by 27 species that cover most of the major genera. Curiously the Phalaenopsis [the second most important pot flower in US commerce] are represented by a man-made hybrid rather the a wild species such as $P$. equestris or amabilis. Even more surprising is the great Cattleyas are missing. The double page is given to Dinema polybulbon [1831; This species is more usually referred to by the 1788 Epidendrum polybulbon - a delightful miniature [mine has just flowered].

So you can find pages on albatross to kinglets, blue whales to shrews and liverworts to spruces. There is a little of everything; bacteria, algae, ferns, trees, fungi, sea life, worms, spiders, crustaceans, insects, fish and frogs. To help the reader the top edges of the seven sections are colour coded. Oddly the plant page corners are tinged purple, not green.
To claim to be the ultimate visual guide to everything on earth is rather sweeping. Any reader will quickly pick out the deficiencies and disparities. There is no mention of enigmatic stalagmites or beautiful sand roses. Nor do pearls of any kind appear in these pages. When a genus is included it may get disproportionate coverage. Only 0.5 percent of willows are pictured, yet the popular penguins get 70 percentage coverage. Lichens, while there are good examples of each type, are only on two pages. If they included all the North Americans lichens alone the book would grow by over 100 pages. The flowering plants show a bias towards the temperate zones. Few Arctic plants are included and the tropical trees tend to disappear into the woodwork [pun!]. Another characteristic I find irritating is the way the publisher has mixed illustration sizes. For example, the $2 \mathrm{~cm}$ Gold Beetle is depicted three times the size of the $7.6 \mathrm{~cm}$ Stag beetle and the $3.2 \mathrm{~m}$ Atlantic Sailfish is eclipsed by the $6 \mathrm{~cm}$ Mandarin fish.

These comments notwithstanding, I think this is a great book to buy, particularly for a family. It is easy to get a broad perspective of the natural world and the format and layout make it simple to use. It is a super reference volume that I will use time and again; I am sure it will grow on me. Perhaps I should paraphrase the sub-title to "The wonderful visual guide to the diversity of life on earth."

ROY JOHN

2193 Emard Crescent, Beacon Hill North, Ottawa, Ontario K1J 6K5

\title{
Essential Ornithology
}

By Graham Scott. 2010. Oxford University Press, 198 Madison Avenue, New York, New York 10016. 172 + x pages. \$55.00 USD Paper.

This is an excellent overview of ornithology, academically sound yet also attractive for amateurs. Graham Scott is an English scientist, the author of the well-received Essential Animal Behaviour (2005). In Essential Ornithology he presents a concise yet comprehensive overview of birds and their biology in a format that is both attractive and innovative.

The book is very well thought out and well organized. The seven chapter titles provide a succinct summary of its contents: "Evolution of birds," "Feathers and flight," "Movement: migration and navigation," "Eggs, nests and chicks," "Reproduction," "Foraging and avoiding predators," and "Populations, communities, and conservation."

Each chapter begins with an interesting or unique quotation, dating from the 18th century through to 2005, and throughout the book Scott reinforces his general arguments with interesting specifics. Key points are highlighted and key references are also provided in the margin. Also in the margin are 9 "Concepts" and 26 "Flight Paths", which provide quick cross-references to entries elsewhere in this book. The book is further enhanced by 29 superb colour photographs, 69 helpful black-and-white figures, 23 box inserts of text (up to two pages long) and one 4-page table of bird Orders and Families.

It is a sign of the times that the journals which Scott cited most often were Nature, Animal Behaviour, Proceedings of the Royal Society: Biology, and Science, with 14, 11, 10 and 10 articles cited, respectively. Of the 44 journal titles cited, only 10 were standard ornithological journals and each was cited only once or twice; Scott's choices highlight the obvious but worrisome (to me) trend toward the ever-diminishing importance of specialized ornithological journals.

The book contains few of the editing errors inevitable in a work of this kind. The Journal volume number or the year of publication is wrong on pages 58 or 109 , $83,100,103$, and110; petechina and bee are misspellings on pages 54 and 98, respectively; and an author's name is spelled both correctly and incorrectly (Stark and Starck) on page 91. 
All in all, this is a delightful book. It is recommended as an introduction to ornithology for new recruits to birding, as an appropriate refresher overview for serious bird students, and as a basic text for a half-class in ornithology.
C. Stuart Houston

863 University Drive, Saskatoon, Saskatchewan S7N 0J8

\section{BOTANY}

\section{North American Native Orchid Conservation - Preservation, Propagation, and Restoration}

By Jyotsna Sharma (Editor). 2009. Conference Proceedings of the Native Orchid Conference, Inc., Green Bay, Wisconsin, June 12-16, 2009. Native Orchid Conference, Inc., P.O. Box 29010, Greensboro, North Carolina 27429-9010. 131 pages, plus CD. \$24.95 USD Soft cover.

As noted in the preface by Clifton (Kip) Knudson (Native Orchid Conference Conservation Committee Chair), the 2009 Native Orchid Conference (NOC) annual meeting held on June 12-16 at the University of Wisconsin campus at Green Bay, Wisconsin, focused on actions to meet the goals of the NOC mission: "to foster the study, conservation, and enjoyment of the native orchids of the United States and Canada." The major goal was to provide information that would assist native orchid habitat conservation. The articles are organized into five sections: conservation, preservation, restoration, propagation, and experimental studies. Sixteen (more than half) of the 21 articles in this proceedings feature conservation, restoration and preservation. There is a welcome focus throughout much of this document on practical conservation effort. The work presented is scientifically sound and the 131 - page publication is well designed and well produced. Editor Jyotsna Sharma and production manager Clifton Knudson are to be complemented on an excellent job. With a wealth of information for a very reasonable price, the Native Orchid Conference Inc. has taken a major step toward the achievement of their stated goals.

The "Orchid Conservation" section includes five articles. The first paper entitled "The role of systematics in orchid conservation," provides some useful information on the ways that systematics can assist in setting orchid conservation priorities. For example newly discovered species have often been overlooked due to their rarity and are likely to require protection. The article entitled "Orchid conservation and the IUCN red list: Platanthera praeclara, a case study" provides a very helpful overview of global status ranking. The method of establishing a protection framework based on representation in different ecological regions is notable and has been applied to crop relatives. Related to this subject of global assessment are assessments done to support listings under the US and Canadian Endangered Species Acts which use similar criteria and function in the same way to provide a basis for protection and recovery programs. It is particularly interesting that in the example, the global and national assessment teams co-operated together in developing an assessment.
The paper entitled "Ethics of plant rescue: what's in it for the plant?," covers a difficult subject with caution and common sense. The author notes that "... plants that are removed to a garden cannot be considered as rescued because they cease to be a part of a reproducing population in a natural plant community." Moving plants is a last resort and moving plants to gardens is generally to be discouraged as long as conservation is the objective. This subject area is related to the idea of the use of transplanting as a conservation tool. Transplanting is best not considered as a conservation tool unless it is based on expert knowledge and follow up and is accompanied by a strong commitment. There is no guarantee of success. It often fails and has been frequently used as a "quick fix" for habitat destruction with disastrous results. Not surprisingly some expert organizations, such as the Canadian Botanical Association, have discouraged the use of simple transplanting as a reliable solution to the destruction of a natural habitat; "The Canadian Botanical Association is strongly opposed to the idea that transplanting is a reliable method of conserving rare species" (http:// www.cba-abc.ca/pospaper.htm, see also Fahselt 1988, 2004, 2006, 2007 and references in Catling 2008). Protecting and managing a natural habitat is more likely to be successful than transplanting because conditions can often be maintained more easily than they can be duplicated (despite our occasional accidental production of great orchid habitat). There is a place for gardens and transplanting in education and recovery, but the limitations and the context needs to be better understood and guidelines, including concepts presented in this article, need to be developed. "Orchid Conservation for the $22^{\text {nd }}$ century" provides a valuable overview of the elements of orchid conservation efforts and suggests both integrated orchid conservation and flexibility. The following and last article in this section, "Orchid food webs," extends the idea of integrated orchid conservation through consideration of orchid food webs. A more thorough understanding of the ecological network that supports a population of orchids has great potential to improve conservation efforts.

The "Orchid preservation" section is particularly valuable in providing help with the basic ground 